\title{
Esoteric Healing Touch—A Preliminary Report
}

\author{
Siddharth Agarwal, Vijai Kumar, \\ Puyush Agarwal, Sapna Agarwal \\ Saran Ashram Hospital, \\ Dayalbagh, India
}

\author{
D. Anand Rao \\ DEI (Deemed University), \\ Dayalbagh, India
}

\begin{abstract}
Human body is a biological, open system and maintains itself in the changing environment. Disease state is cured by many medicinal systems for healing. Esoteric healing is the system where its believers regard Supreme Being as Omnipotent, Omnipresent and Omniscient. Such persons take ill health as a boon and pray through meditation that He may by His Mercy grant health or if God wishes otherwise, they happily accept it so that they keep moving ahead on their spiritual path. A study has been done on 217 hospitalized patients over 18 months. Cure rates between the ordinary patients and those with Esoteric thinking have been compared. Results clearly point towards better cure in patients who believe in esoteric healing.
\end{abstract}

Keywords: Biological system, Dayalbagh, Esoteric healing, faith

\section{Introduction}

Change is the order of life. Wherever we look, things either develop or evolve or rundown and decay. Human body, being a complete biological system, is an open system in a steady state. Openness refers to the energy import activities of the system, which it needs to maintain its own dynamic steady state.

Thus human system maintains itself and a healthy body in a changing environment.

The process of running down may be due to excessive physical and mental strain causing damage to cells and their structures that make our body or due to attack of external disturbing factors which could not be absorbed by the body system, thereby producing temporary or permanent ill effects or erratic effects on the normal functioning of such humans. These conditions are the diseases of the human body system and they may be cured to varying extents by the contemporary medicine.

\section{Review of Literature}

Medical Systems for healing:

(1) Naturopathy: this system advocates cure through special treatments taken from nature like mud packs, oil baths, medicated spring waters (sulphur spring) or regulating the dietary habits, etc..

(2) Ayurvedic system: natural resources in their raw form, like plants and their parts or products with tested medicinal properties or their combinations can cure certain diseases.

Siddharth Agarwal, MBBS MD, Saran Ashram Hospital; member of SSI, Dayalbagh Chapter.

Vijai Kumar, MD, MRCP, Advisor ME \& HCP Dayalbagh, Saran Ashram Hospital; member of SSI, Dayalbagh Chapter.

Puyush Agarwal, MBBS, MS, Saran Ashram Hospital; member of SSI, Dayalbagh Chapter.

Sapna Agarwal, MBBS, MD, Saran Ashram Hospital; member of SSI, Dayalbagh Chapter.

D. Anand Rao, Professor Emeritus (Retd), DEI (Deemed University); member of SSI, Dayalbagh Chapter. 
(3) Homeopathic system: this is based on the principle that small doses in the form of dilutions (potency) of the material producing the same symptoms as that of the disease, can remove the cause of the disease with those symptoms, e.g., snake poison in its proper dilutions can cure the patient of snake bite.

(4) Biochemic system: a healthy body is in a state of equilibrium of 12 basic salts of the human system and any deficiency of salt or salts disturbs the balance and causes disease. Supply of the salts in deficiency cures the disease.

(5) Allopathy system: is modern medicinal system which is evidence based. That is disease is cured by a drug or treatment protocol which has been tested in a controlled trial. This system has limitations that, it often involves intervention on patient, the drugs used can sometimes be more harmful and it is expensive.

(6) Yoga system: controlling and regulating the habits to lead a disciplined life with regular exercises to keep muscles, limbs and joints fit. Faced with health problems, yoga can also cure the diseases.

(7) Cure by religious practices: When someone is cured of terminal cancer, or comes out of coma, is this a miracle? And what of those who do, indeed, die of their disease in a state of "grace"? Faith healers talk about miracles all the time whereas modern medicine tends towards super specialist science and intervention. And alternative health practitioners from naturopaths to chiropractors and counselors tend to fall somewhere in the middle.

It may be noticed that in the medicine system 1 to 5 , the effectiveness of the medicine administered depends upon the ability of the doctor to correctly compare the patients' symptoms with the characteristics of the medicine. If there is a mismatch, the medicine may not cure the patient and they may also produce undesirable side effects.

One of the questions that skeptics are asked most persistently is to explain how acupuncture, homeopathy, faith healing, qigong and other treatments work. Skeptics often attribute this to placebo effect-a response to the act of being treated, not the treatment — as the answer John E. Dodes (1997) in his article "The Mysterious Placebo" believes that both logical and fuzzy thinkers, don't truly understand what the placebo effect is. Belief in the treatment, operant conditioning, and power of suggestion all play important roles (Jarvis, 1990).

The Duke University study used church and synagogue attendance as a measure of religiosity. Researchers studied 3,968 residents of northern California who were 64 to 101 years of age, during a 6 year period. At follow up, $29.7 \%$ of the participants have died. The relative hazard of dying was $46 \%$ lower for those who attended religious services frequently (at least once per week). After excluding significant variables, the mortality rate of churchgoers was $28 \%$ lower than those who do not (Duke University study group, 2000).

Another study that used attendance of religious services as a gauge of religiosity was conducted over a 28 year period in 5,286 residents of Alameda County, California (1997). In this study also mortality rate was lower in persons who attended religious services frequently. The author attributed this to the fact that frequent attendees had less exposure to certain risk factors for hastened death (for example, smoking, alcohol abuse, and limited social contacts).

In a study by Harris and coworkers, attendance of worship services was not included in the methods (Harris et al., 1999). The author studied 990 patients who were admitted consecutively to a coronary care unit and were randomly assigned to receive intercessory prayer for 4 weeks. The patient did not know that the prayers were being offered. Although length of hospital stay did not differ between the prayer and nonprayer group, the patients who received Intercessory prayer had lower coronary care unit severity "scores". 
Dale A Mathews, author of The Faith Factor, book on health and religion defines religiosity as a person's adherence to the beliefs and practices of organized religion. Only a few studies have focused on spirituality, which is much more difficult to gauge; Mathews defines it as a person's search for meaning or for personal relationship with a higher power. Studies of religion effect on health often assess religiosity by determining frequency of attendance at worship services. This can be easily measured; persons, perceptions of their relationships with a higher power cannot (Dale, 1999).

Roxianne Moore in his paper says that healing works on the whole person rather than just the symptom (Roxianne, 2005). Curing can come on many levels, but works more on the physical level. Healing comes from the Anglo-Saxon "to make whole".

Lyall Watson, a biologist who's been looking at the miracles of nature and the Concept of holism for many years talks about what is involved in natural healing.

Many medical schools around the world now offer such courses, largely because patients are demanding more spiritual care. According to a Newsweek poll, $72 \%$ of Americans say they would welcome a conversation with their physician about faith; same number say they believe that praying to God can cure someone- even if science says that person doesn't stand a chance (Claudia, 2003).

From the above it can be inferred that, in the cure by religious practices, cure depends upon the faith of the patient in the system.

\section{Esoteric Healing}

We all have faith on one thing or other, one person or the other, unconditional surrender to the Adept or God or religion Head or in His Faith.

Esoteric school of thinking regards the Adept or God or Supreme Creator or Supreme Being as Omnipotent, Omnipresent, and Omniscient.

The Supreme Creator is Omnipotent because He is a reservoir of infinite energy, Who has created the entire universe. He is Omnipresent because such a high energy creates a spiritual force field (Quantum Spiritual Force Field) around, which is spread in the entire universe. We all know that our physical universe is pervaded by four Quantum Force Fields (Strong Nuclear, Electromagnetic, Weak Nuclear and Gravitational Force Field in descending order of their intensities). However, there is a prime spiritual force field which contains the prime or original spiritual energy whose fountainhead is Radhasoami Dayal, the supreme Creator. The Quantum Field of that source of spirit forces pervades the whole macrocosmic creation and is omnipresent (Satsangi, 2010). He is Omniscient because His individual spirit forces, which are the sentient entities, pervade the entire creation. These spirit forces interact with the matter and material of the physical world to produce living organisms.

Believers of the Esoteric thinking and those who agree with the above hypothesis, try with all their faculties, i.e., body, mind, and soul to reach God through meditation. Such persons take ill health also as a boon and pray through meditation that, He may by HIS Mercy, grant health to enable them to fulfill the purpose for which they are born and living in this world.

If God grants them cure through decay and rejection of the foul cells and regeneration of new replacement cells by giving medical intuition to the attending doctor or otherwise, and then they work for their ultimate goal with new vigor. If God wishes otherwise, still they feel happy and accept graceful death so that they keep moving ahead in their spiritual path. 
This is the Esoteric Healing Touch where patient gets satisfaction either way, i.e., cure or living with the problem or death.

A study has been done on patients registered in a Nursing Home over a period of 18 months, and has been carried out to assess and compare the cure rates among the ordinary patients and patients who believe in Esoteric thinking and belong to a community of Dayalbagh which is a spiritual Ashram in Agra.

\section{Aims and Objectives}

The present study has been undertaken with the following aims and objectives:

(1) To see the effect of prayer in healing of ailments in hospitalized patient.

(2) Does common faith in Higher Power of both, treating doctor as well as patient, has any bearing on outcome.

(3) What effect if any, do firm faith in God and HIS WILL, produce in terminally ill patients.

(4) Is there any mortality difference among the patients, those having firm faith in God and those not so firm or not at all.

\section{Material and Methods}

Total of 213 patients who were hospitalized, over a period of 18 months were divided into 2 groups as follows:

Group A: patients in this group belong to a community having common Faith in Supreme Power (Esoteric thinking), have a unique pattern of lifestyle, and were involved in regular prayer (themselves or their attendants) during hospital stay. The treatment decision making and options were influenced by Faith and religion in this group. Total number in this group is 107.

Group B: Patients in this group were from general population, and did not have a common belief and faith, and prayers if practiced were infrequent. The medical and treatment decision making in this group was not influenced by religion and therefore totally guided according to medical science. Total patients in this group were 106.

Primary End points were:

(1) Complete Cure;

(2) Death.

Secondary End points were:

(1) Palliation of Disease (that is only temporary relief of problem and not cure).

(2) Left the Institute against medical advice.

(3) Shifted to or referred to other hospital.

This was a purely observational study and patients were not forced any treatment options. Patients were evaluated in two broad disease groups of Non-Communicable and Infective or communicable diseases. Non-communicable diseases were further sub categorized into 6 disease groups as: Cardiac, Cancer, Neuropsychiatry, Gastrointestinal and Respiratory and Diabetes.

\section{Observations and Results}

Table 1 shows the cure rate of patients in percentage in different disease groups. 
Table 1

Cure Rates Comparison Between Gp-A (Esoteric) and Gp-B (Non-esoteric).

\begin{tabular}{lll}
\hline Disease & Gp-A & Gp-B \\
\hline I. Infectious diseases & $94.8 \%$ & $76.19 \%$ \\
II. Non-communicable & & \\
Diseases: & & \\
Cardiac & $90.9 \%$ & $75 \%$ \\
Cancer & $66.6 \%$ & $50 \%$ \\
Neuropsychiatry & $83.3 \%$ & $63.6 \%$ \\
Gastrointestinal & $84.21 \%$ & $77.27 \%$ \\
Respiratory & $83.3 \%$ & $62.8 \%$ \\
Diabetes and hypertension & $87.5 \%$ & $73.3 \%$ \\
\hline
\end{tabular}

Patients with diabetes who presented with some complication due to diabetes were labeled as cure when that complication was cured and not Diabetes per se.

Table 2 shows comparison of outcome between Groups A and B.

Table 2

Outcome Comparison After Intervention Between Gp-A and Gp-B.

\begin{tabular}{lcc}
\hline Outcome & Group A & Group B \\
\hline$N$ & 107 & 106 \\
Cured & $95(88.7 \%)$ & $82(78 \%)$ \\
Palliation & $7(6.5 \%)$ & $3(2.8 \%)$ \\
Left the Institute (against Medical advice) & $0(0)$ & $13(12.2 \%)$ \\
Shifted to other hospitals & $1(.93 \%)$ & $4(3.7 \%)$ \\
Deaths & $4(3.7 \%)$ & $4(3.7 \%)$ \\
\hline
\end{tabular}

\section{Discussion}

Above observations clearly point towards better cure rate in group A patients who believe in esoteric healing: $88.8 \%$ in group A as compared to $78 \%$ in group B. 13 patients from group B left the treatment against medical advice, while none left from group A, again stressing the fact that, group A patients were ready to accept either of the outcomes and considered disease and its outcome to be the Will of their God.

Deaths rates were the same in both the groups. Those who died in group A did accept this fact that they are going to die, gracefully, and moreover, their relatives did not force the treating doctor to use any life supporting and resuscitative equipment like intubation and ventilator during their terminal stage. They in fact prayed at that time for the departing soul.

More numbers from Group A preferred conservative treatment, rather than intervention or surgical treatment. Hence a little more of them were given only palliative treatment, where the disease was incurable, like advanced cancer and paralysis

This is a preliminary report; hence statistical methods have not been applied to determine the level of significance of outcomes. But figures, definitely point towards better healing in those with esoteric thinking and belief.

\section{References}

Attendance of religious services study in residents of Almeda County. (1997). California: Am. J. Public Healtrh, 87, $957-961$. 
Claudia, K. (2003). Faith and healing. Newsweek, 12.

Dale A. M. (1999). The Faith Factor. Penguin Books.

Duke University study group. (2000). Faith and Healing article. Annals of Internal Medicine, 132(2), 169-172.

Harris et al. (1999). Arch Int. Medicine, 159, 2273-2278.

John, E. D. (1997). The mysterious placebo. Skeptical Inquirer Magazine, Jan/Feb.

Roxianne, M. (2005). The role of faith in healing. Suite 101.

Satsangi, P. S. (2010). Expositions on truth, ultimate reality and supreme being (From vantage points of Radhasoami Faith and Systems Science) (p. 89). Radhasoami Satsang Sabha, Dayalbagh (Agra). 